\title{
Adaptation of Virulent Field Isolate of Duck Plague Virus (DPV) in Embryonated Chicken Eggs
}

\author{
Sivasankar Panickan* \\ Immunology Section, Indian Veterinary Research Institute, \\ Izatnagar-243122, Uttar Pradesh, India \\ *Corresponding author
}

Keywords

Duck plague virus, Duck embryo, Chicken embryo, Serial passage

Article Info

Accepted:

17 January 2021

Available Online:

10 February 2021
In this study, we report adaptation of virulent field isolate of duck plague virus (DPV)/duck enteritis virus (DEV) in chicken embryo for the purpose of vaccine development. Naturally DEV field isolates are resistant to grow in chicken embryos and are not pathogenic to chicken embryo, unless few preliminary passages were given in embryonated duck eggs or duck embryo fibroblast cell culture. Historically, 12-20 number of duck embryo passages was reported to adapt the virus in chicken embryo. Here, we are first time reporting prerequisite of 50 number of serial passages in duck embryo to adapt the virus. The adapted virus killed the chicken embryo and was confirmed by PCR.

\section{Introduction}

Duck plague is one of the most common viral disease of ducks in India (Mukerji et al., 1963; Rajan et al., 1980; Bhowmik and Ray, 1987; Kulkarni et al., 1995). It is caused by Anatid alpha herpesvirus-1 also known as duck enteritis virus (DEV)/duck plague virus (DPV) which belongs to Herpesviridae family ( $\mathrm{Li}$ et al., 2009), causes an acute disease with high mortality in ducks, geese and swans of all age groups. Usually the affected birds show depression, enteritis and paralysis of legs and dies within 4-5 days. Although this disease effectively controlled by live attenuated vaccine (Holland strain) in India which is in use for more than 60 years (Jansen, 1961), currently this vaccine is produced from embryonated chicken eggs which has some bottlenecks.

Many researchers have produced chicken embryo adapted indigenous vaccine from field isolate with promising results (John et al., 1989; Bordolai et al., 1994; Hossain et al., 2005). However, to prepare vaccine from field isolates the virus has to be adapted and attenuated in chicken embryos. In this study, 
with the goal of developing improved vaccine for duck plague the technique of adaptation of DEV in chicken embryo was described with our experience.

\section{Materials and Methods}

\section{Duck plague virus (DPV)}

DPV positive duck liver samples were collected from an natural outbreak in Kerala, India and the virus was earlier isolated by duckling inoculation and confirmed by PCR \& sequencing of DNA polymerase gene of the virus, NCBI accession no: KX511893 (Panickan et al., 2020). The virus was maintained in the form of $10 \%$ liver suspension at $-80^{\circ} \mathrm{C}$.

\section{Duck and chicken embryos}

Duck eggs were collected from ducklings maintained in animal house and incubated at $37^{\circ} \mathrm{C}$ for growth of embryo up to 9-11 day old. Embryonated chicken eggs were purchased from Central Avian Research Institute (CARI), IVRI, Izatnagar.

\section{Preparation of viral inoculum}

Infected duck liver tissue $(0.5 \mathrm{~g})$ was sonicated and diluted in $10 \mathrm{ml}$ of Phosphate buffered saline (PBS) with recommended concentration antibiotic (Gibco). The suspension was centrifuged at $>12000 \mathrm{rpm}$ for 15 minutes at $4^{\circ} \mathrm{C}$ to pellet the tissue debris and the clear supernatant was collected aseptically and incubated at $37^{\circ} \mathrm{C}$ for one hour before inoculating the embryos.

\section{Procedure for Chorio-Allantoic Membrane (CAM) route of inoculation}

Entire procedure was performed aseptically in Laminar airflow cabinet. 9-12 days old live embryonated duck eggs were selected and air sac was marked with help of egg candler.
After wiping the whole surface of eggs with $70 \%$ ethanol. A fine hole was made in the center of the air sac using egg puncher and another hole was on egg shell surface, just below $2-3 \mathrm{~cm}$ of air sac marking, the site free of blood vessels and embryo movement. using small size of rubber bulb mild suction (negative pressure) was applied through air sac hole. Due to negative pressure, chorionic membrane got slight detachment from the egg shell membrane under the surface second hole (called membrane dropping), creating a artificial space between the egg shell membrane and chorionic membrane. In this artificial space $0.1-0.2 \mathrm{ml}$ of viral inoculum was deposited using tuberculin syringe. After the injection, both holes were sealed with paraffin wax and the eggs were incubated $37^{\circ} \mathrm{C}$ at horizontal position for first $24-48$ hours, injected surface pointing upwards, later it was incubated vertically and the eggs were monitored for death of embryo. If death occurs within $24 \mathrm{hrs}$, it was considered as non specific which probably due to contamination/toxicity/ large size of membrane dropping.

\section{Serial passaging in duck embryo}

During first passage, liver suspension was used as inoculum. After death of the duck embryo, CAM was processed as above and used for serial passaging in duck embryo. Thus 50 number of passages were carried out. At intermittent passages, the virus was checked for its adaptation/growth in chicken embryo by giving blind passages.

\section{Serial passaging in chicken embryo}

The DEV from $50^{\text {th }}$ passage of duck embryo CAM tissue was sonicated, processed as above and inoculated into two 9-11 day old white leghorn chicken embryo (CE) by CAM route. After death of the chicken embryo CAM was collected, processed and injected 
into duck embryo. In this way, few alternate passage was made, then continuous serial passage was done in chicken embryo by CAM route. The presence of virus in the duck/chicken embryo at various passage levels were detected by PCR targeting the DNA polymerase genes as per the standard protocol (Panickan et al., 2020).

\section{Results and Discussion}

During serial passaging in duck embryo (DE), initially DEV took 5-6 days to kill the embryo but in subsequent passages, embryo died exactly on $4^{\text {th }}$ day with typical lesions for duck plague due to well adaptation of virus but when nearing $50^{\text {th }}$ passage again it took 5-6 days to kill. This prolonged time to kill, may be due to partial attenuation/reduction in virulence of the virus. The infected embryo showed severe hemorrhage (cherry red embryo) particularly at occipital region and legs with edematous condition. The CAM was found to be thickened and hemorrhagic (Panickan et al., 2020). After $50^{\text {th }}$ passage in duck embryo the virus was started to grow in chicken eggs and killed the embryo (first passage in CE). At intermittent passages in $\mathrm{DE}$, we attempted blind passage in CE to check adaptation which showed no death of $\mathrm{CE}$ and PCR was negative for viral DNA. CAM was harvested from first passage of chicken embryo which died due to DEV and serial passages were attempted in CE, but the virus failed to grow in subsequent serial passages. So, the virus was passed alternatively through duck (5pass) and chicken embryo (5 pass), then it got fully adapted, showed growth in $\mathrm{CE}$ in subsequent serial passages. The growth of virus in embryos was detected by death of embryo/PCR. During initial passages in $\mathrm{CE}$, there was no lesion but in subsequent passages it killed the chicken embryo quickly and showed typical lesions of duck plague as seen in duck embryo. During serial passages in $\mathrm{DE} / \mathrm{CE}$ the presence of virus tracked by PCR which showed amplification of DNA polymerase gene with $446 \mathrm{bp}$. Prior workers have reported 12-20 number of passages to adapt the virus in chicken embryo (John et al., 1989; Bordolai et al., 1994; Hossain et al., 2005) but in our study it took 50 passages which may be due to high virulence of this isolate. We hypothesize that number of passage required in DE to adapt in $\mathrm{CE}$ correlates with virulence of the isolate. i.e. less virulent isolate may require less no. of passages in DE, high virulent isolate may need high no. of passage in DE. Since, our isolate may be with more virulent it would have taken 50 passages in DE which might have resulted in partial attenuation of virus. This partial attenuation perhaps aided the DEV to adapt in CE. The molecular changes that occurs in genome of the virus while DE passage that helps in adaptation in CE is not clear. This research gap has to be studied further which may add knowledge on adaptation of viruses in heterologous host system.

\section{Acknowledgments}

The author is thankful to the Director, Joint Director (Research) and Joint Director (Academic), ICAR- Indian Veterinary Research Institute (Deemed University) for providing the necessary facilities to undertake the study.

\section{References}

Bhowmik, M.K and Ray, M.M. 1987. Enteric diseases in ducks (Anas platyrhynchos domesticus). Indian Vet Med J. 11: 209-214.

Bordolai, G.K., Boro, B.R., Mukit, A., Sharma, K. and Dutta, G.N. 1994. Adaptation and attenuation of duck plague virus for vaccine production. Indian Vet. J. 71(7): 639-644.

Hossain, M.T., Islam, M.A., Amin, M.M. and Islam, M.A. 2005. Comparative 
Efficacy of the Conventional and Experimentally Developed Duck Plague Vaccine. Int. J. Poult. Sci. 4(6): 369-371.

Jansen, J. 1961. Duck plague. Br Vet J. 117: 349-356.

John, K., Sarma, D.K., Boro, B.R., Das, S.K. and Muku, A. 1989. Attenuation and pathogenicity of a locally isolated strain of duck plague virus. Indian J. Anim. Sci. 60(6): 615-617.

Kulkarni, D.D., James, P.C and Sulochana, S. 1995. Isolation of duck plague virus from ducks in Kerala state. Indian Vet. J. 72: 446-450.

Li, Y., Huang, B., Ma, X., Wu, J., Li, F., Ai, W., Song, M. and Yang, H., 2009. Molecular characterization of the genome of duck enteritis virus.
Virology. 391: 151-161.

Mukerji, A., Das, M. S., Ghosh B. B. and Ganguly, J. L. 1963. Duck plague in West Bengal-Part II. Indian Vet. J. 40: 753-758.

Panickan, S., Dandapat, S., Kumar, J., Mahendran, M., Nandi, S. and Punnoose, P. 2020. Molecular characterization and pathogenicity of an Indian isolate of duck enteritis virus recovered from a natural outbreak. Ind. J. Anim. Res. (Accepted).

Rajan, A., Nair, M. K., Maryamma, K. and Valsala, K.V. 1980. Studies on the epidemiology, symptoms and pathoanatomy of duck plague infection (duck viral enteritis). Indian Vet. J. 57: 12-15.

\section{How to cite this article:}

Sivasankar Panickan. 2021. Adaptation of Virulent Field Isolate of Duck Plague Virus (DPV) in Embryonated Chicken Eggs. Int.J.Curr.Microbiol.App.Sci. 10(02): 1962-1965. doi: https://doi.org/10.20546/ijcmas.2021.1002.235 